\title{
Relationship between Deflection and Contact Area of Drive Tire
}

\author{
Ş. Ekinci, K. Çarman, M. Taşyürek, and M. Mirik
}

\begin{abstract}
Tires are important parts of every vehicle including tractors and other off-road vehicles. Thus, structural and operational characteristics determination of the tires is too important. Tire deflection and tire contact area are functions of tractive performance. In this study an electronic system was designed in order to determine deflection of the tire. Deflection and contact area experiments were conducted by means of single wheel tester. As a result; the effects on deflection of dynamic axle load and inflation pressure were found significant $(\boldsymbol{P}<0.01)$ by utilizing variance analysis. There was a linear relationship between deflection and contact area of tire. The deflection of the tire increased with dynamic axle load for all inflation pressures tested. The deflection decreased with increasing inflation pressure. Additionally, increase in the tire load and decrease in the tire inflation pressure lead to bigger the tire contact area.
\end{abstract}

Index Terms - Contact area, deflection, dynamic load, inflation pressure, tire.

\section{INTRODUCTION}

One of the most important tire properties is the modulus of elasticity, the relation between the applied force and tire deformation. Deflection is a term that it describes the bulge that forms at the bottom of a loaded tire. That bulge is instead the result of the deflection. The tire deflection depends on tire carcass stiffness, structure (cross ply or radial), ply rating (number of structure layers), tire inflation pressure, of which, the tire inflation pressure is the dominant determining factor for tires [1]. Deflection is a key parameter and many equations have been developed based on it to evaluate the tractive performance of tires operating in cohesive-frictional soils. Gross traction, rolling resistance, net traction and tractive efficiency are predicted as a function of the tire deflection [2]. Too high a deflection increases rolling resistance [3].

Several methods are used to determine tire deflection. The most widely used conventional method is the one based on static deflection only that can be determined by measuring the tire cross section height and by applying the equation $[\delta=(\mathrm{OD} / 2)-(\mathrm{SLR})]$ developed by Brixius [4] to calculate the deflection (ASAE S296.4) [5]. Lyasko [6] measured

Manuscript received March 19, 2015; revised July 28, 2015. This work was supported by the Scientific and Technological Research Council of Turkey by the project number: 113 O 794.

Ş. Ekinci is with the Department of Mechanical Engineering, Selçuk University, Konya, 42003, Turkey (e-mail: sekinci@ selcuk.edu.tr).

K. Çarman is with the Department of Agricultural Machinery, Selçuk University, Konya, 42003, Turkey (e-mail: kcarman@selcuk.edu.tr).

M. Taşyürek is with the Department of Metallurgical and Materials Engineering, Selçuk University, Konya, 42003, Turkey (e-mail: mtasyurek@selcuk.edu.tr).

M. Mirik is with the Rail Systems Machine Technology Programme, Cumhuriyet University, Sivas, Turkey (e-mail: mmirik@cumhuriyet.edu.tr). deflection for 20 tires by this way, on a rigid surface under various vertical loads and inflation pressures. Taylor et al. [7] measured load-deflection data at three inflation pressures by increasing the static load and measuring static loaded radius (SLR) as the tire rested on a smooth metal plate. Tiwari et al. [8] conducted on the hard surface deflection and zero condition tests by this way. Rashidi et al. [2] designed and constructed a tire deflection test apparatus to measure deflection of tires with different sizes at diverse levels of inflation pressure and vertical load. The static loaded radius was obtained by measuring the deflection as deflection on a hard surface is equal to $d / 2$ minus the measured static loaded radius. The other method that is based on dynamic deflection is the one that employs electronic measurement systems when the test tire is running at certain speeds. In a study conducted by Koca [9] on a vehicle, investigations of effects of varying tire inflation pressures at certain speeds on the dynamic radius and deflection of the tire under laboratory conditions were made. The researcher determined the deflection amount of an automobile tire placed on a chassis dynamometer by using a Linear Variable Differential Transformer at certain speeds. Traction force that can be developed by the driving tire is a function of the contact between the ground and the tire. There exists a linear relationship between the contact and the tire's projection area. Contact area is a function of slip angle and deflection [10]. Tire width, contact surface and profile play an important role in selection of tires. Carrying capacity of tires depends on structure of tires, air volume and inflation pressure. Because of changing operation loads on tires, it is important for tire manufacturers to specify optimum inflation pressures to prevent tire damages. To improve draw force of tires during field operation, contact area of tires should be increased by lowering inflation pressure. Inflation pressure has also a remarkable influence on tire performance When there is an increase of load on tire about two times, tire contact area increases at a rate of $30-40 \%$ while tire connection area decreases at a rate of $70-80 \%$ when inflation pressure becomes two times bigger [11].

The contact area also depends on the rolling resistance. The internal resistance relates here to the dissipated energy within the tire that is mainly dependent on the hysteresis of the material used and therefore the tire deformation [12]. Kumar and Dewangan [13] used $6.00 \times 12-4 \mathrm{PR}$ tires for determining contact characteristics of the tire. They performed the experiments under five levels of inflation pressure and six levels of normal load. A white paper was placed at the center of a steel plate and a blue carbon paper was placed on the paper. The carbon paper was covered with a drawing sheet. The tire was raised and rotated by few degrees to obtain a good imprint of the tire on the white paper by overlaying a number of prints on the same area. The outline of the contact 
area imprint was traced and the contact area was determined using a digital planimeter. Raheman and Singh [10] for a fixed normal load, and inflation pressure, run a test trolley in the soil bin and marked area coming in contact with the tire on the soil surface. They traced out the contact area with a marker pen by pressing a transparent paper on the marked area and later measured with the help of a planimeter. In this way, they measured contact area for various combinations of external load, inflation pressure.

\section{MATERIALS AND METHODS}

280/70R20 radial type of tire was used at experiments. Table I shows the values of the parameters for the tire manufacturer In order to determine tire deflection, a newly developed deflection measuring device and a single wheel tester to be used in traction performance tests were used (Fig. 1 and Fig. 2). The measuring set consists of an electric motor located in a canal, a transmission with a 4 -speed range and 2 drums. With the transmission, it is possible to drive the drums at four different speeds. The power transfer from the electric motor to the transmission is achieved by using a belt-pulley mechanism.

TABLE I: TIRE DIMENSIONAL CHARACTERISTICS

\begin{tabular}{lllll}
\hline \hline Tire size & $\begin{array}{l}\text { Overall } \\
\text { diameter } \\
(\mathrm{mm})\end{array}$ & $\begin{array}{l}\text { Section } \\
\text { width } \\
(\mathrm{mm})\end{array}$ & $\begin{array}{l}\text { Tire carrying } \\
\text { capacity }(\mathrm{kg})\end{array}$ & $\begin{array}{l}\text { Load Index } \\
\text { and Speed } \\
\text { Symbol }\end{array}$ \\
\hline $280 / 70 \mathrm{R} 20$ & 912 & 282 & $710-1640$ & $\begin{array}{l}116 \mathrm{~A} 8 / \\
116 \mathrm{~B} 8\end{array}$ \\
\hline \hline
\end{tabular}

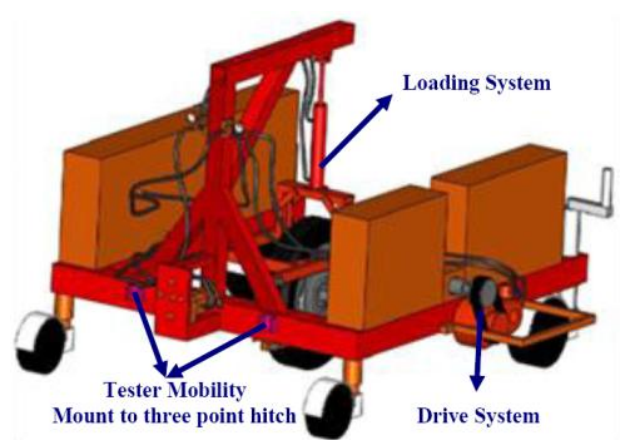

Fig. 1. Single wheel tester design concept.

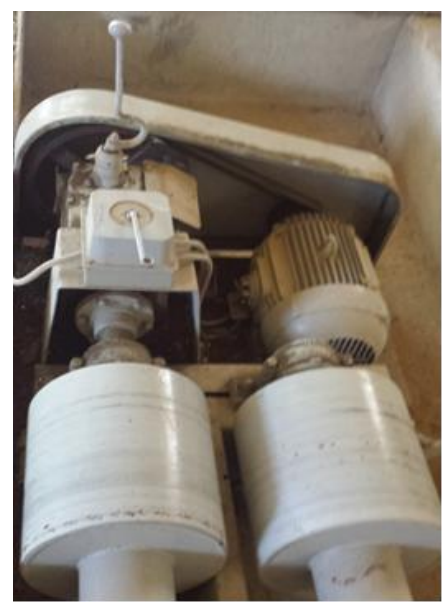

Fig. 2. Deflection measuring device.

In the tests involving deflection measurements, a 220 VAC-24 VDC convertor, a data logger, a linear displacement transducer and a deflection testing system were used.
Electronic device of deflection testing system is shown in Fig 3.

The inflation pressures of the 280/70R20 size driving tire specimen used in the tests were selected based on the manufacturer's catalogue instructions by assigning the values of $62,103,137,179,220,241$ and $275 \mathrm{kPa}$. As for the tire deflection, the specimen was subjected to four rotational speeds of 60, 100, 150 and 200 rpm while loaded with 3.0, 4.5, 6.0 and $7.5 \mathrm{kN}$ of axial loads respectively.
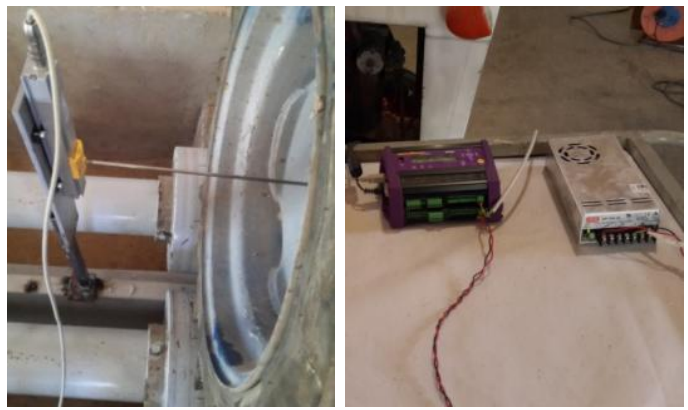

Fig. 3. Data detection and storage unit of deflection measuring device.

Through the loading unit, the axial loads were applied by taking the single wheel tester developed for different grounds onto the drums of the deflection measuring device. The amounts of deflection were recorded to the data logger by using the linear displacement transducer mounted onto the tire center with a shaft. The distance between the tire center and the drum before loading, the distance after application of the axial load with the static deflection and the distance after running the drums with the dynamic deflection were determined.

To determine contact areas of the tire on concrete surface, experiment tire was lifted with lever jack and partly painted and then lowered on an A3 sized paper which was placed under lifted tire at every axle load and inflation pressure. This procedure was repeated 4-5 times while tire was rotated 5-10 at every experiment to fill contact area. Contact areas on papers were transferred to electronic data with SigmaPro Scan $^{\mathrm{TM}}$ software. The paper containing the trace area first scanned to computer and then the digital form was prepared for the SigmaPro Scan ${ }^{\mathrm{TM}}$ software via Photoshop ${ }^{\mathrm{TM}}$ software after pixels of the residual paint were cleared via MS paint ${ }^{\mathrm{TM}}$ software.

Variance analyses of manipulated variables such as dynamic load, inflation pressure and wheel speed were done in order to determine effects on deflection values. MINITAB $^{\mathrm{TM}}$ program was used to obtain the results of variance analysis which was done via ANOVA module.

\section{RESULTS AND DISCUSSION}

When looking at the tire's deflection values based on the tire inflation pressure, it is found that as the inflation pressure increases the amount of deflection decreases. In the Fig. 4, the variations of static deflection with the applied axial load and the dynamic deflection with the inflation pressure after running the tire are observed. As the axial load increases, the deflection increases because of the load distribution within the tire as far as the tire's shape is concerned (Fig. 5). In study conducted by Raheman and Sing [10], it was found that the 
axial load and tire inflation pressure have linear relationship with the tire deflection. According to the study by Kumar and Dewangan [13], the increase in axial load is supported by the tire's inflation pressure while the decrease in axial load is supported by the skeletal nature of the tire.

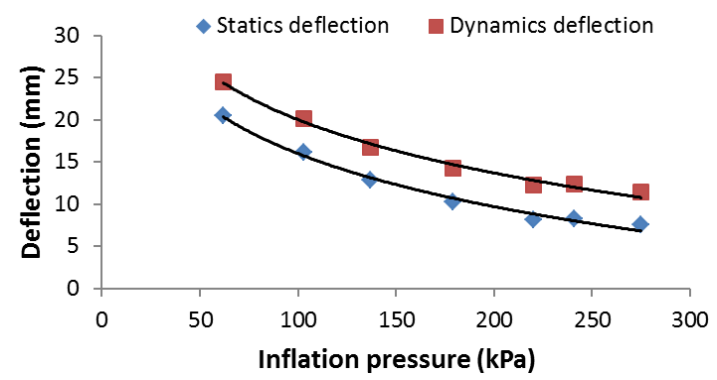

Fig. 4. Effect of inflation pressure on deflection at average load.

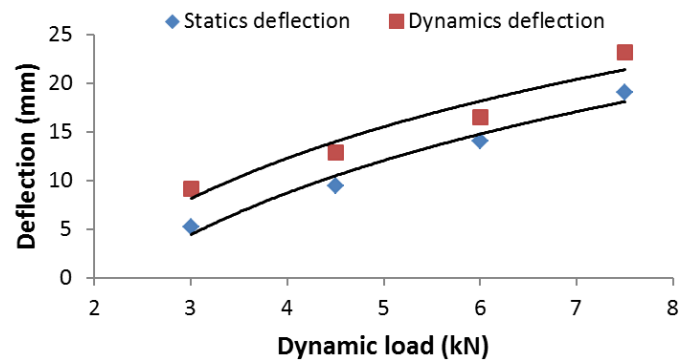

Fig. 5. Effect of dynamic load on deflection at average inflation pressure.

The effects of wheel speed on the deflection are shown on the Fig. 6. As the speeds increase the tire deflections seem to increase just sparingly. As it is also seen from the graph, it can therefore be concluded that, the increase in speed has no significant influence on the deflection of the tire.

Fig. 7 is presented to shows the scatterplots of correlation between deflection values versus the contact area values. The results of tests show that for the tire deformation process the dependence between characteristics deflection and contact area is linear.

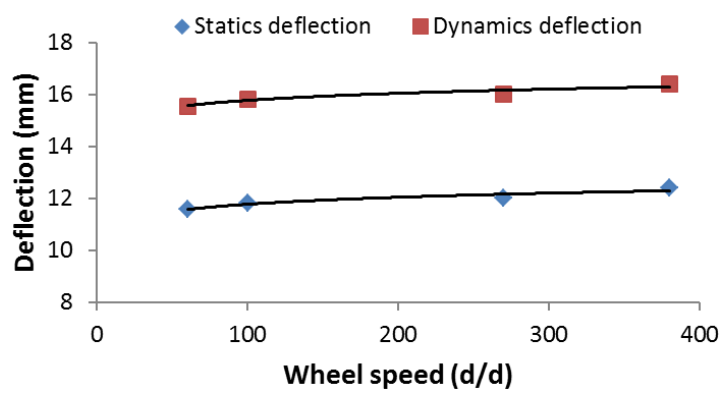

Fig. 6. Effect of wheel speed on deflection at average inflation and pressure dynamic load.

Contact area of tires changed between $237-497 \mathrm{~cm} 2$ with different inflation pressures during experiments (Fig. 8). An approximate $30 \%$ increase in inflation pressure of tire leaded to a $10 \%$ decrease in contact area. Schwanghart [11] reported that a two times increase in tire inflation pressure leads to $70-80 \%$ decrease in tire contact area. Diserens [12] expressed that for a cross-ply tire (28L-26) under a low load, if its inflation pressure varies from 150 to $180 \mathrm{kPa}(+20 \%)$, the contact area increases $(+9 \%)$. With a $70 \%$ higher loading rate, however, and the same pressure variation, the contact surface area is smaller $(10 \%)$. When the tire is under a light load, the volume of the tire subject to increased inflation pressure increases (balloon effect), and the contact area increases. Above a particular load threshold, the inflation pressure is insufficient to counter the load, so the tire distorts under the weight and the contact area increases.

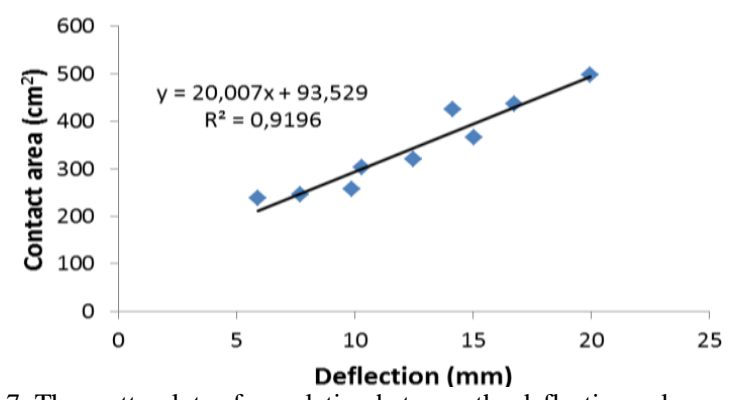

Fig. 7. The scatterplots of correlation between the deflection values versus the contact area values.

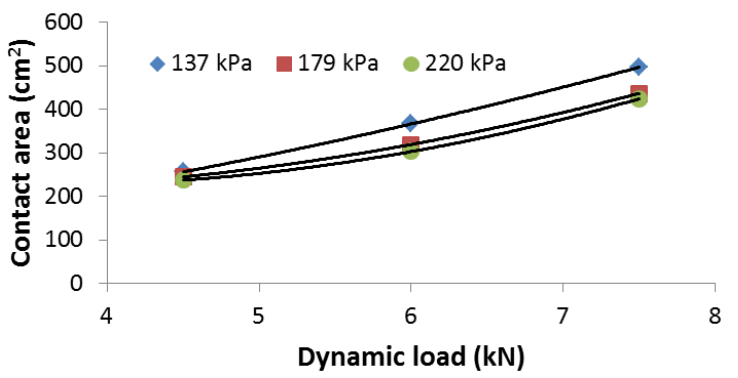

Fig. 8. Variation of tire contact area against dynamic load at different inflation pressures.

When effects of tire load on contact area is considered, it can be expressed that $67 \%$ increase in tire load causes $84 \%$ tire contact area increase in radial tire. Flanks of radial tires are softer and elastic. Plies provide more and homogenous contact surface by making carcass harder structure. In case of cross-ply tires, harder flanks and softer body provide smaller contact area. Therefore, contact area of cross-ply tire presents a smaller increase than radial tire under load.

Analysis of variance (ANOVA) was developed for the effects of dynamic load, inflation pressure and wheel speed interactions for deflection (Table II). As appreciated from Table II, effect of dynamic load, inflation pressure and wheel speed on deflection was found to be important $(P<0.01)$.

When tire contact area geometry is investigated, it can be seen that area geometry is ellipse at $220 \mathrm{kPa}$ bar inflation pressure and $4.5 \mathrm{kN}$ load while it resembles rectangular at 137 $\mathrm{kPa}$ inflation pressure and $7.5 \mathrm{kN}$ load. Similarly, tire contact area is geometrically ellipse at low loads while it resemble rectangular at high loads (Fig. 9).

TABLE II: THE ARRANGEMENT OF CHANNELS

\begin{tabular}{lcccc}
\hline \hline \multicolumn{1}{c}{ VS } & DF & SS & MS & F- Statistics \\
\hline Inflation pressure & 6 & 2276,782 & 379,464 & $35,15^{* *}$ \\
Dynamic load & 3 & 3034,811 & 1011,604 & $93,07^{* *}$ \\
Wheel speed & 3 & 10,461 & 3,487 & $25,84^{* *}$ \\
$\begin{array}{l}\text { Inflation } \\
\text { pressure*Dynamic }\end{array}$ & 18 & 194,296 & 10,794 & $180,71^{* *}$ \\
$\begin{array}{l}\text { load } \\
\text { Inflation } \\
\text { pressure*Wheel }\end{array}$ & 18 & 1,595 & 0,089 & $1,48^{\text {ns }}$ \\
speed & & & & \\
$\begin{array}{l}\text { Dynamic } \\
\text { load*Wheel speed }\end{array}$ & 9 & 1,214 & 0,135 & $2,26^{\text {ns }}$ \\
$\begin{array}{l}\text { Error } \\
\text { Total }\end{array}$ & 54 & 3,226 & 0,060 & \\
$\quad * * 1 \%$ level was statistically $(P<0.01)$ & ns not significant. \\
\hline \hline
\end{tabular}




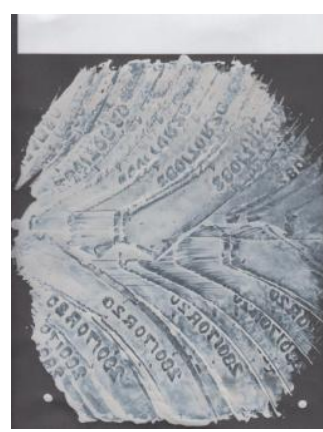

a)

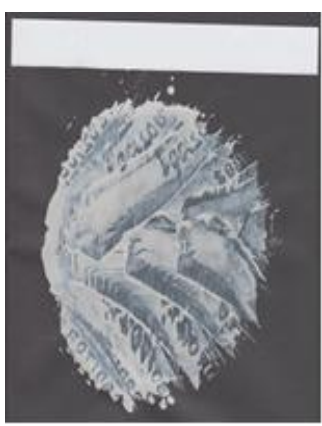

b)
Fig. 9. Tire contact area geometries at different inflation pressures a) $220 \mathrm{kPa}$, $4.5 \mathrm{kN}$, b) $137 \mathrm{kPa}, 7.5 \mathrm{kN}$.

\section{CONCLUSION}

Based on the experiment conducted with the range of tire inflation pressure (62-275 kPa) and dynamic load (3-7.5 kN), findings can be summarized as following;

The tire deflection linearly decreased with an increase in inflation pressure at constant normal load while it linearly increased with an increase in normal load at constant inflation pressure. Excessive deflection of a tire causes high rolling resistance, overheats the tire and accelerates wear of its surface. Therefore, an optimum inflation pressure should be determined in order to maximize tire performance. The influence of the inflation pressure is more significant than dynamic loads.

The tire contact area decreases as inflation pressure increases. Decreasing contact area leads to a decrease in draw force, and increases in soil deformation and slippage. Tire contact area increases while load is increased due to tire structure.

Between the contact area and the deflection was determined linear relationship. For a pneumatic tire the contact area depends on tire deflection, influenced by tire inflation pressure and wheel load; but it also depends on the elasticity of the soil.

The deflection measurement method, which needs only one tractive performance parameter, will make it simpler and ideal candidate for use in deflection studies.

\section{ACKNOWLEDGMENT}

The authors acknowledge the support of this study by the Scientific and Technological Research Council of Turkey by the project number: 113 O 794 .

\section{REFERENCES}

[1] M. Saarilahti, "Soil interaction model project deliverable D2 (Work Package No. 1)," in Proc. Development of a Protocol for Ecoefficient Wood Harvesting on Sensitive Sites, 1999-2002, pp. 33-39.

[2] M. Rashidi et al., "Prediction of radial-ply tire deflection based on contact area index, inflation pressure and vertical load," J. Agric. \& Environ. Sci., vol. 13, no. 3, pp. 307-314, April 2013.
[3] D. R. Lee and K. U. Kim, "Effect of inflation pressure on tractive performance of bias-ply tires," Journal of Terramechanics, vol. 34, no. 3, pp. 187-208, May 1997.

[4] General Terminology for Traction of Agricultural Tractors, Self-propelled Implements, and Traction and Transport Devices, ASAE Standards ASAE S296.4-1995.

[5] W. W. Brixius, "Traction prediction equations for bias ply tires," ASAE Paper No. 87-1622, p. 8, 1987.

[6] M. I. Lyasko, "The determination of deflection and contact characteristics of a pneumatic tire on a rigid surface," Journal of Terramechanics, vol. 31, no. 4, pp. 239-246, July 1994.

[7] R. K. Taylor, L. L. Bashford, and M. D. Schrock, "Methods for measuring vertical tire stiffness," Transactions of the ASAE, vol. 43, no. 6, pp. 1415-1419, Nov./Dec. 2000.

[8] V. K. Tiwari et al., "A review on traction prediction equations," Journal of Terramechanics, vol. 47, pp. 191-199, June 2010.

[9] A. Koca, "Lastik hava basıncı ve taşıt hızının dinamik yarıçap değişimine etkilerinin deneysel olarak incelenmesi,” Gazi Üniv. Müh. Mim. Fak. Dergisi, vol. 22, no. 3, pp. 305-311, 2007.

[10] H. Raheman and R. Singh, "Steering forces on undriven tractor wheel," Journal of Terramechanics, vol. 40, pp. 161-178, July 2003.

[11] H. Schwanghart, "Measurement of contact area, contact pressure and compaction under tires in soft soil," Journla of Terramechanics, vol. 28, no. 4, pp. 309-318, 1991

[12] E. Diserens, "Calculating the contact area of trailer tyres in the field," Soil Till. Res., vol. 103, no. 2, pp. 302-309, May 2009.

[13] G. V. P. Kumar and K. N. Dewangan, "Deflection and contact characteristics of a power tiller tyre," Agricultural Engineering International: The CIGR EJournal, vol. 6, pp. 1-8, Jan. 2004.

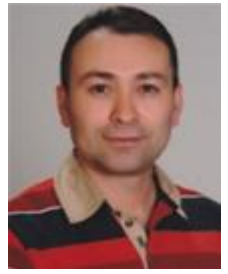

Paragra Şerafettin Ekinci is with the Department of Mechanical Engineering, Technology Faulty, Selçuk University, Konya, Turkey. He was born in Sivas, Turkey, in 1971, who received his $\mathrm{PhD}$ degree in agricultural machineries from Konya, Turkey in Sept 2011, with major field of traction mechanics. His research interests are traction performance, tire and tribology. He is a member of IACSIT.

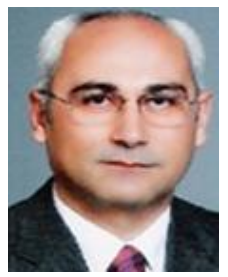

Kazım Çarman was born in 1961, Kayseri, Turkey. $\mathrm{He}$ received his $\mathrm{PhD}$ degree from Selçuk University of Turkey. He is currently a professor at the Department of Agricultural Machinery, Selçuk University. $\mathrm{He}$ is interested in traction performance and tillage.

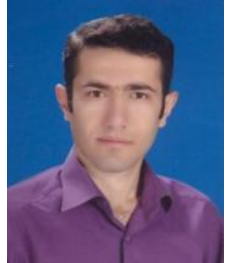

Mustafa Taşyürek was born in 1982, and received his $\mathrm{PhD}$ degree in mechanical education from Selçuk University, Turkey in 2014. From 2005 to present, he is a research assistant with Selçuk University. Currently, he is a research assistant at the Department of Metallurgical and Materials Engineering, Selçuk University, Turkey. His research interests are in nanomaterials, nanocomposites and mechanical properties. He is a member of IACSIT.

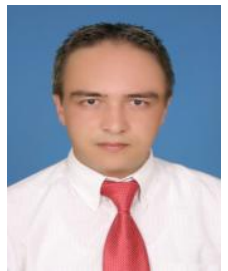

Murat Mirik was born in 1982. He received his master degree in machine training from Selçuk University, Turkey in 2010. Currently, he is a lecturer at the Rail Systems Machine Technology Programme, Cumhuriyet University, Turkey. His main research interest includes nanocomposite materials. 